\title{
METASTATIC THYMIC CARCINOMA OF SCALP: A CASE REPORT
}

\author{
Pranveer Singh Rao ${ }^{1}$, Thoppil Reba Philipose ${ }^{2}$
}

${ }_{1}^{1}$ Post Graduate Student, Department of Pathology, AJ Institute of Medical Sciences, Mangalore.

2Professor, Department of Pathology, AJ Institute of Medical Sciences, Mangalore.

\section{ABSTRACT}

\section{BACKGROUND}

Thymic carcinomas are epithelial neoplasm of the thymus exhibiting clear malignant cytologic or architectural features. Extrathoracic metastasis of thymic carcinomas are rare.

\section{CASE REPORT}

A 42-year-old male diagnosed with thymic carcinoma six months back and who had completed three cycles of Paclitaxel and Carboplatin and on palliative radiotherapy was referred to the Department of Surgery with painful swelling on the temporal aspect of scalp. Microscopic examination showed highly cellular smears consisting of oval-to-spindle shaped cells mixed with larger epithelial cells.

\section{CONCLUSION}

The case highlights an occurrence of distant metastasis of thymic carcinoma to an unusual site. We wish to emphasize the role of cytology in early diagnosis of scalp swellings with metastasis from rare or unusual malignancies.

\section{KEYWORDS}

Metastasis, Carcinoma, Thymus.

HOW TO CITE THIS ARTICLE: Rao PS, Philipose TR. Metastatic thymic carcinoma of scalp: a case report. J. Evolution Med. Dent. Sci. 2016;5(28):1466-1467, DOI: 10.14260/jemds/2016/344

\section{INTRODUCTION}

Thymic carcinomas are epithelial neoplasm of the thymus exhibiting clear malignant cytologic or architectural features. Extrathoracic metastasis of thymic carcinomas are rare.[1] Metastasis of thymic carcinoma has been reported to the liver, lymph node, bone, brain, gastrointestinal tract, kidney, ovary, spleen, pancreas, breast and skin.[2] One case with scalp metastasis was reported in recent literature. The cytologic diagnosis of thymoma is challenging, because these neoplasms are uncommon and rarely aspirated.[3]

\section{CASE REPORT}

A 42-year-old male diagnosed with thymic carcinoma six months back and who had completed three cycles of Paclitaxel and Carboplatin and on palliative radiotherapy was referred to the Department of Surgery with painful swelling on the temporal aspect of scalp. Examination revealed a firm, fixed, tender and ulcerated swelling. X-ray skull showed no erosion of the underlying cranial bone. Fine needle aspiration was done under strict aseptic precaution. Microscopic examination showed highly cellular smears consisting of oval-to-spindle shaped cells mixed with larger epithelial cells. The nuclear cytoplasmic ratio was moderate-to-high and mitoses were infrequent.

Financial or Other, Competing Interest: None.

Submission 16-02-2016, Peer Review 14-03-2016,

Acceptance 19-03-2016, Published 07-04-2016.

Corresponding Author:

Dr. Pranveer Singh Rao,

\#201, Heights-C,

Landlinks,

Mangalore

Karnataka,

E-mail: pranveer_rao_184@yahoo.com

DOI: $10.14260 /$ jemds $/ 2016 / 344$
The scalp swelling was excised and the tissue was submitted for histopathologic evaluation, which confirmed metastatic carcinoma with morphology similar to the primary thymic carcinoma.

\section{DIAGNOSIS}

Metastatic Thymic Carcinoma of Scalp.

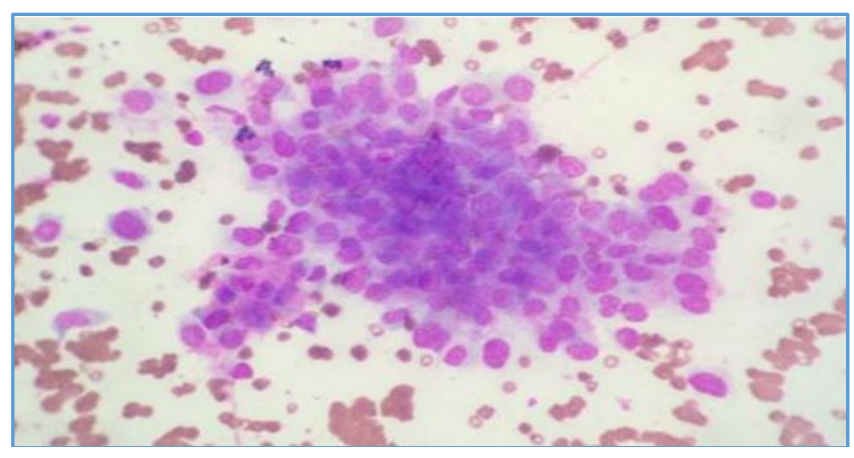

Fig. 1: Spindle Shaped Cells Admixed with Large Epithelial Cells and Pseudo-Rosette formation

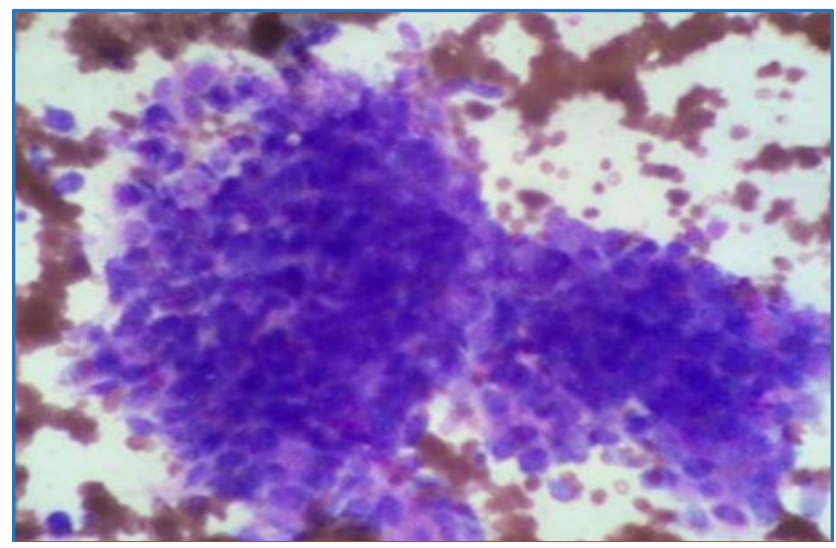

Fig. 2: Thick Cluster of Epithelial Cells which Precludes individual Cell Morphology 


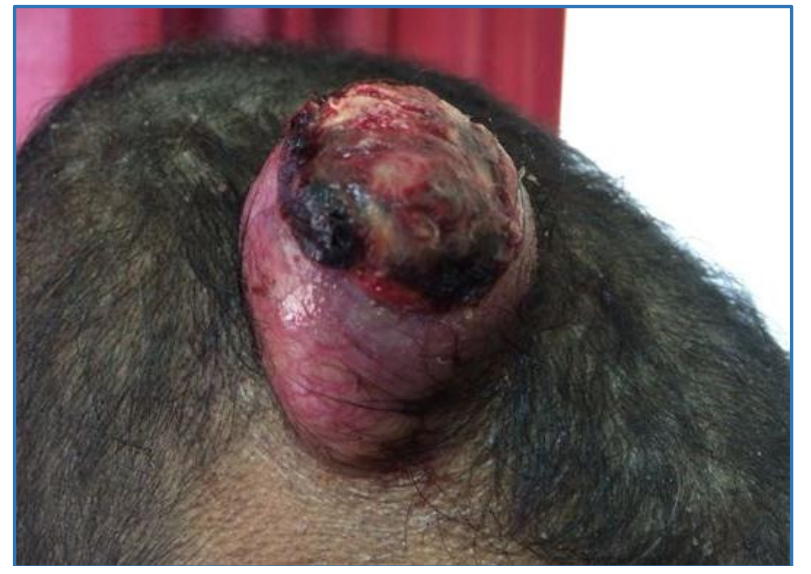

Fig. 3: Ulcerated Swelling on the Temporal aspect of Scalp

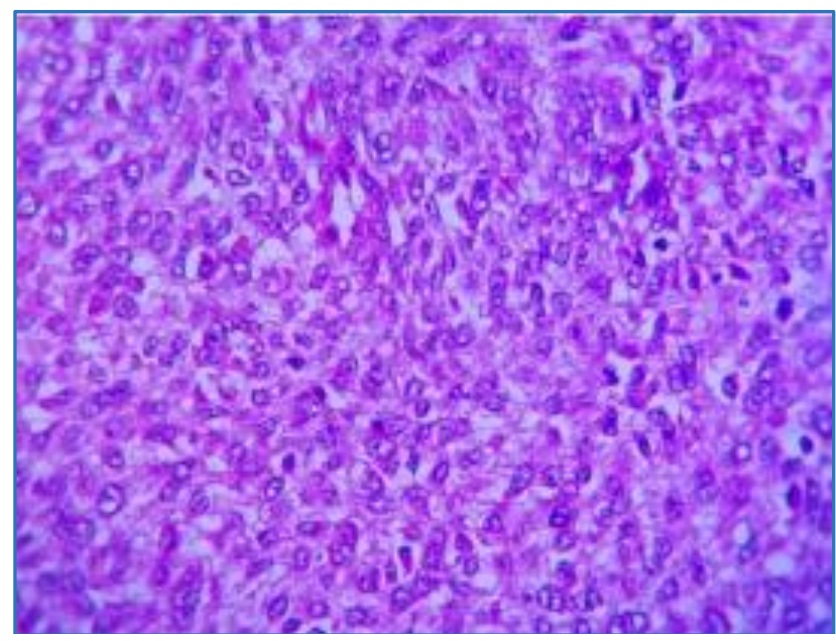

Fig. 4: Vesicular Nuclei with Anisokaryosis and Irregularly Clumped Chromatin. H\&E Stain (High power)

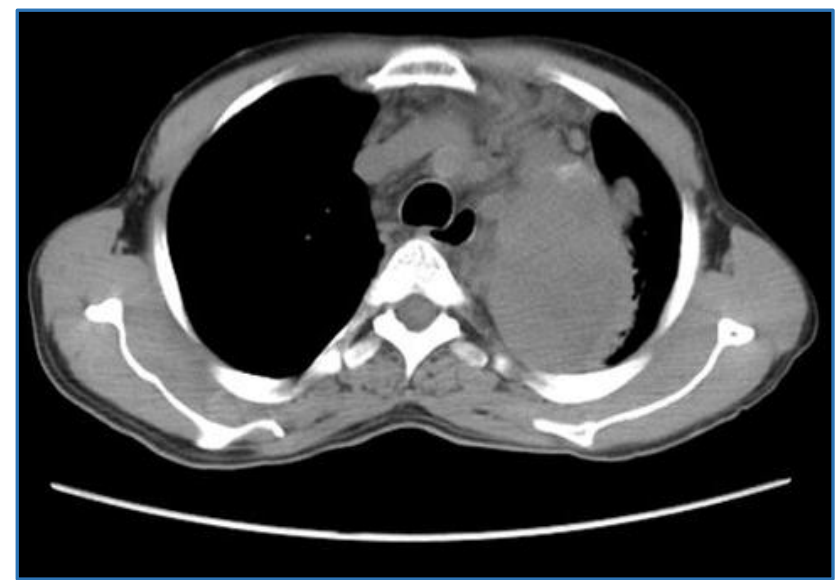

Fig. 5: Anterior Mediastinal Mass with Heterogeneous Enhancement and Compression of Left Lung

\section{DISCUSSION}

Microfragments of malignant epithelial cells lies in a necrotic background.

The thickness of the fragment precludes detailed evaluation of individual cell morphology.

Epithelial cells in thymic carcinoma display overt malignant features. Spindle shaped cells admixed with large epithelial cells. High nuclear cytoplasmic ratio and infrequent mitoses are seen.

\section{CONCLUSION}

The case highlights an occurrence of distant metastasis of thymic carcinoma to an unusual site. We wish to emphasize the role of cytology in early diagnosis of scalp swellings with metastasis from rare or unusual malignancies.

\section{REFERENCES}

1. Wakely PE Jr. Fine needle aspiration in the diagnosis of thymic epithelial neoplasms. Hematol Oncol Clin North Am 2008;22(3):433-42.

2. Wakely PE Jr. Cytopathology of thymic epithelial neoplasms. Semin Diagn Pathol 2005;22(3):213-22.

3. Vladislav T, Jain RK, Alvarez R. Extrathoracic metastases of thymic origin: a review of 35 cases. Mod Pathol 2012;25(3):370-7. 